\title{
Identification of a 4-IncRNA signature predicting prognosis of patients with non-small cell lung cancer: a multicenter study in China
}

\author{
Rui-Qi Wang ${ }^{1 \dagger}$, Xiao-Ran Long ${ }^{1,2 \dagger}$, Chun-Lei Ge ${ }^{3 \dagger}$, Mei-Yin Zhang ${ }^{1}$, Long Huang ${ }^{4}$, Ning-Ning Zhou ${ }^{5}$, \\ $\mathrm{Yi} \mathrm{Hu}^{1,6}$, Rui-Lei Li ${ }^{3}$, Zhen Li ${ }^{3}$, Dong-Ni Chen ${ }^{1,6}$, Lan-Jun Zhang ${ }^{1,6}$, Zhe-Sheng Wen ${ }^{1,6}$, Shi-Juan Mai ${ }^{*}$ \\ and Hui-Yun Wang ${ }^{1,7^{*}}$ (D)
}

\begin{abstract}
Background: Previous findings have indicated that the tumor, nodes, and metastases (TNM) staging system is not sufficient to accurately predict survival outcomes in patients with non-small lung carcinoma (NSCLC). Thus, this study aims to identify a long non-coding RNA (InCRNA) signature for predicting survival in patients with NSCLC and to provide additional prognostic information to TNM staging system.

Methods: Patients with NSCLC were recruited from a hospital and divided into a discovery cohort $(n=194)$ and validation cohort $(n=172)$, and detected using a custom IncRNA microarray. Another 73 NSCLC cases obtained from a different hospital (an independent validation cohort) were examined with qRT-PCR. Differentially expressed IncRNAs were determined with the Significance Analysis of Microarrays program, from which IncRNAs associated with survival were identified using Cox regression in the discovery cohort. These prognostic IncRNAs were employed to construct a prognostic signature with a risk-score method. Then, the utility of the prognostic signature was confirmed using the validation cohort and the independent cohort.

Results: In the discovery cohort, we identified 305 IncRNAs that were differentially expressed between the NSCLC tissues and matched, adjacent normal lung tissues, of which 15 are associated with survival; a 4-IncRNA prognostic signature was identified from the 15 survival IncRNAs, which was significantly correlated with survivals of NSCLC patients. This signature was further validated in the validation cohort and independent validation cohort. Moreover, multivariate Cox analysis demonstrates that the 4-IncRNA signature is an independent survival predictor. Then we established a new risk-score model by combining 4-IncRNA signature and TNM staging stage. The receiver operating characteristics $(\mathrm{ROC})$ curve indicates that the prognostic value of the combined model is significantly higher than that of the TNM stage alone, in all the cohorts.
\end{abstract}

\footnotetext{
*Correspondence: maisj@sysucc.org.cn; wanghyun@mail.sysu.edu.cn

${ }^{\dagger}$ Rui-Qi Wang, Xiao-Ran Long and Chun-Lei Ge contributed equally to this

work

${ }^{1}$ State Key Laboratory of Oncology in South China, Collaborative

Innovation Center for Cancer Medicine, Sun Yat-Sen University Cancer

Center, Guangzhou 510060, China

${ }^{7}$ State Key Laboratory of Oncology in South China, Sun Yat-Sen

University Cancer Center, 651 Dongfeng East Road, Building 2, Rm 704,

Guangzhou 510060, China
}

Full list of author information is available at the end of the article

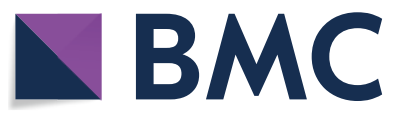

(c) The Author(s) 2020. This article is licensed under a Creative Commons Attribution 4.0 International License, which permits use, sharing, adaptation, distribution and reproduction in any medium or format, as long as you give appropriate credit to the original author(s) and the source, provide a link to the Creative Commons licence, and indicate if changes were made. The images or other third party material in this article are included in the article's Creative Commons licence, unless indicated otherwise in a credit line to the material. If material is not included in the article's Creative Commons licence and your intended use is not permitted by statutory regulation or exceeds the permitted use, you will need to obtain permission directly from the copyright holder. To view a copy of this licence, visit http://creativeco mmons.org/licenses/by/4.0/. The Creative Commons Public Domain Dedication waiver (http://creativecommons.org/publicdomain/ zero/1.0/) applies to the data made available in this article, unless otherwise stated in a credit line to the data. 
Conclusions: In this study, we identified a 4-IncRNA signature that may be a powerful prognosis biomarker and can provide additional survival information to the TNM staging system.

Keywords: Non-small cell lung cancer (NSCLC), Long non-coding RNA (IncRNA), Signature, Prognosis, TNM stage

\section{Background}

Lung cancer is the most common and lethal malignant disease in the world, and approximately about $85 \%$ of lung cancer cases are non-small cell lung cancer (NSCLC) [1]. In clinical practice, delayed diagnosis and the lack of effective prognostic biomarkers are two main reasons for poor survival of patients with NSCLC $[2,3]$. The 5 -year survival rate for patients with late-stage lung cancer and those with stage-I lung cancer is $15 \%$ and $83 \%$, respectively [4]. Currently, the treatment strategy and prognosis of lung cancer are mainly determined according to TNM staging system. However, NSCLC patients with the same TNM stage may have a different prognosis $[2,5,6]$. Therefore, an urgent need exists for new biomarkers that can help improve the accuracy of prognosis prediction, which would enhance the quality of life of patients as well as the survival rate $[7,8]$.

With the development and advancement of highthroughput technologies, numerous investigators have proposed using single genes or gene sets (signatures) as biomarkers for tumor diagnosis, prognosis, disease classification, and personalized treatment. Genomic abnormalities such as DNA mutations, copy-number variations, DNA methylation, and gene expression have been investigated for their usefulness in identifying prognostic biomarkers in patients with NSCLC. High-throughput technologies like microarray and RNA-sequencing (RNA-seq) have enabled simultaneous analysis of hundreds or thousands of genes and their relationships with clinical features, including the survival of patients with cancer, which has led to the discovery of many novel biomarkers (single genes or signatures) for diagnosis, prognosis, and targeted therapy in patients with NSCLC [9, 10]. However, only a few molecular biomarkers have been evaluated in clinical practice (mainly as therapeutic targets) [11] because most of the biomarkers show low accuracy (low sensitivity and/or specificity) [12] or need to be further confirmed with a larger population in an independent validation study [13]. Therefore, more reliable biomarkers are still needed to improve diagnosis, prognosis and personalized therapy for NSCLC patients.

Long non-coding RNAs (lncRNAs) that are expressed at high levels in the body have exhibited superior potential as novel diagnostic or prognostic biomarkers when compared to protein-coding genes, which raises the possibility of identifying more reliable biomarkers for lung cancer $[14,15]$. LncRNAs are a type of non-coding RNA that are longer than 200 nucleotides [16, 17]. Accumulating reports have shown that lncRNAs can participate in numerous biological processes, such as the regulation of epigenetic modification, cell cycle progression, and cell differentiation. Growing evidence shows that numerous lncRNAs are significantly deregulated in various types of cancers and play important roles in tumorigenesis [18-20]. An increasing number of lncRNAs have been shown to be dysregulated and involved in lung cancer tumorigenesis, and to be useful as diagnostic or prognostic biomarkers, or as targets for therapy. For example, the lncRNAs MALAT1 and NEAT1 play important roles in lung cancer cell proliferation, cell cycle progression, and apoptosis, as well as tumor progression and prognosis [21-25]. Inhibitors targeting MALAT1 significantly reduced lung cancer metastasis in a mouse model [21]. The prognostic role of IncRNA signatures in NSCLS has been investigated in many reports by using the data downloaded from the Gene Expression Omnibus (GEO) database or The Cancer Genome Atlas (TCGA) database. However, a lncRNA expression profile for especially identifying prognostic signature in a large cohort of NSCLC patients and multicenter study has not been reported yet. Therefore, the prognostic value and the clinical application potentiality of lncRNA signature in NSCLC patients are necessary to be further systematically explored.

In this study, to our knowledge, we performed the first multicenter retrospective study on the prognosis of total 439 NSCLC patients with a custom lncRNA microarray and qRT-PCR. NSCLC patients from South China were randomly divided into a discovery cohort (194 cases) and a validation cohort (172 cases), and those from Southwest China were used as an independent validation cohort (73 cases). A 4-lncRNA signature was established to predict survival of NSCLC patients in the discovery cohort, and was validated in the validation and independent cohorts.

\section{Methods}

\section{Patients and clinical information}

A total of 439 NSCLC cases were collected for this study, and these patients underwent radical resection of lung cancer in the Sun Yat-Sen University Cancer Center $(\mathrm{n}=366)$ and Yunnan Cancer Hospital $(\mathrm{n}=73)$ between 2003 and 2008. Matched cancer tissues and adjacent normal tissues were obtained from each patient recruited in Sun Yat-Sen University Cancer Center. The inclusion criteria for our study were: (i) NSCLC was confirmed by 
pathological diagnosis and reviewed by 2 experienced pathologists, (ii) the patients did not receive any form of anti-tumor therapy before surgery, (iii) the patients did not die within 1 month after surgery, and (iv) the patient's sample was preserved at $-80{ }^{\circ} \mathrm{C}$ immediately after surgery. The samples collected from the 366 patients enrolled at Sun Yat-Sen University Cancer Center were divided randomly into a discovery cohort $(\mathrm{n}=194)$ and a validation cohort $(n=172)$. Seventy-three patients with NSCLC were recruited from Yunnan Cancer Hospital (using the inclusion criteria described above) and assigned to an independent validation cohort. Overall Survival (OS) was defined as the time from the date of surgery to the date of death or last follow-up, and disease-free survival (DFS) was defined as the time from the date of surgery to the date of first recurrence or distant metastasis, death, or the last follow-up. The clinicopathological characteristics of the patients in all three cohorts are shown in Table 1. This study was reviewed and approved by the Ethical Committees of Sun Yat-Sen University Cancer Center and Yunnan Cancer Hospital. Written informed consent was obtained from each patient.

\section{RNA extraction}

RNA was extracted from tumor and normal lung tissues using the TRIzol reagent (Invitrogen, Carlsbad, CA, USA) and homogenized with a Bullet Blender (VortexGenie 2), according to the manufacturer's instructions. Briefly, each tissue $(100 \mathrm{mg})$ was mixed with $1 \mathrm{~mL}$ TRIzol reagent and homogenized in a Bullet Blender at a $4{ }^{\circ} \mathrm{C}$ for $15 \mathrm{~min}$, after which the mixtures were incubated at $25^{\circ} \mathrm{C}$ for $5 \mathrm{~min}$. After adding chloroform, the mixtures were violently shaken for $15 \mathrm{~s}$, incubated at room temperature for $10 \mathrm{~min}$, and then centrifuged for $15 \mathrm{~min}$ at $4{ }^{\circ} \mathrm{C}$ and 14,000 rotations per min. After each supernatant was transferred to a new tube, an equal volume of isopropyl alcohol was added, and the tube contents were mixed. After holding the tubes at room temperature for $10 \mathrm{~min}$, the supernatants were discarded after centrifugation. Each precipitate was washed with $75 \%$ alcohol, and then the ethanol was removed after additional centrifugation. After allowing the residual ethanol to evaporate, doubledistilled $\mathrm{H}_{2} \mathrm{O}$ was added to dissolve the RNA. Finally, the concentration and quality of each extracted RNA was measured in an ND-1000 spectrophotometer (NanoDrop Technologies), to meet the requirements of the microarray and qRT-PCR experiments.

\section{Quantitative RT-PCR}

Total RNA $(1 \mu \mathrm{g})$ was reverse transcribed using the GoScript $^{\mathrm{TM}}$ Reverse Transcription System (Promega), which includes oligo $(\mathrm{dT})$ primers and random primers
Table 1 Clinical characteristics of the patients with NSCLC analyzed in the study

\begin{tabular}{|c|c|c|c|}
\hline Parameters & $\begin{array}{l}\text { Discovery } \\
\text { cohort } \\
(\mathrm{N}=194)\end{array}$ & $\begin{array}{l}\text { Validation } \\
\text { cohort } \\
(\mathrm{N}=172)\end{array}$ & $\begin{array}{l}\text { Independent } \\
\text { cohort } \\
(\mathrm{N}=73)\end{array}$ \\
\hline Age $(X \pm S D)$ & $59.2 \pm 10.1$ & $59.8 \pm 10.2$ & $57.6 \pm 9.1$ \\
\hline \multicolumn{4}{|l|}{ Gender } \\
\hline Male & $144(74.2 \%)$ & $136(79.1 \%)$ & $52(71.2 \%)$ \\
\hline Female & $50(25.8 \%)$ & $36(20.9 \%)$ & $21(28.8 \%)$ \\
\hline \multicolumn{4}{|l|}{ TNM stage } \\
\hline 1 & 87 (44.8\%) & $74(43.0 \%)$ & $23(31.5 \%)$ \\
\hline$\|$ & $32(16.5 \%)$ & $34(19.8 \%)$ & $20(27.4 \%)$ \\
\hline III & 75 (38.7\%) & $64(37.2 \%)$ & $30(41.1 \%)$ \\
\hline \multicolumn{4}{|l|}{ Histological type } \\
\hline$A D C$ & $95(49.0 \%)$ & $89(51.7 \%)$ & $47(64.4 \%)$ \\
\hline SCC & $88(45.3 \%)$ & $76(44.2 \%)$ & $26(35.6 \%)$ \\
\hline $\mathrm{ADC} / \mathrm{SCC}$ & $11(5.7 \%)$ & $7(4.1 \%)$ & $0(0.0 \%)$ \\
\hline \multicolumn{4}{|l|}{ Tumor size $(\mathrm{cm})$} \\
\hline$<5$ & $108(55.7 \%)$ & 97 (56.4\%) & $31(42.5 \%)$ \\
\hline$\geq 5$ & $86(44.3 \%)$ & 75 (43.6\%) & $42(57.5 \%)$ \\
\hline \multicolumn{4}{|l|}{ Differentiation } \\
\hline Well/moderate & $126(64.9 \%)$ & $105(61.0 \%)$ & $43(58.9 \%)$ \\
\hline Poor & $68(35.1 \%)$ & $67(39.0 \%)$ & $30(41.1 \%)$ \\
\hline \multicolumn{4}{|c|}{ Lymphatic metastasis } \\
\hline No & $105(54.1 \%)$ & $81(47.1 \%)$ & $45(61.6 \%)$ \\
\hline Yes & $89(45.9 \%)$ & 91 (52.9\%) & $28(38.4 \%)$ \\
\hline \multicolumn{4}{|c|}{ Follow-up time (month) } \\
\hline Median (IQR) & $37(24-62)$ & $36(23-54 \%)$ & $22(14-35)$ \\
\hline \multicolumn{4}{|l|}{ Smoking history } \\
\hline No & $79(40.7 \%)$ & $62(36.0 \%)$ & $33(45.2 \%)$ \\
\hline Yes & $115(59.3 \%)$ & $110(64.0 \%)$ & $40(44.8 \%)$ \\
\hline \multicolumn{4}{|c|}{ Family cancer history } \\
\hline No & $161(83.0 \%)$ & $151(87.8 \%)$ & 71 (97.3\%) \\
\hline Yes & $33(17.0 \%)$ & $21(12.2 \%)$ & $2(2.7 \%)$ \\
\hline
\end{tabular}

$S D$ standard deviation, $A D C$ adenocarcinoma, $S C C$ squamous cell carcinoma, $I Q R$ inter-quartile range

for the reverse transcription step, and qPCR was performed using GoTaq ${ }^{\circledR}$ qPCR (Promega) and SYBR Green on a PRISM 7900HT system (Applied Biosystems). Each sample was analyzed in triplicate wells, and reactions without cDNA were included as negative controls. The thermal cycling conditions were as follows: $94{ }^{\circ} \mathrm{C}$ at $5 \mathrm{~min}$ (for the hot start step), followed by 40 cycles at $94{ }^{\circ} \mathrm{C}$ for $15 \mathrm{~s}$ and $60{ }^{\circ} \mathrm{C}$ for $30 \mathrm{~s}$. The sequences of the primers used in this study are shown in Additional file 1: Table S1. The PCR data were processed by normalizing the median expression value of a given lncRNA to the expression of GAPDH in the same sample. Relative lncRNA-expression levels were quantified using the $2^{-\Delta \Delta \mathrm{Ct}}$ method. 


\section{LncRNA microarray fabrication and hybridization}

Human lncRNA transcript sequences selected from public lncRNA databases, including the LNCipedia, LncRNAdb, LncRNADisease, and EST databases, were used to design probes for constructing an lncRNA microarray, and 2412 probes were successfully designed. The lncRNA microarray was fabricated in-house and hybridized as described previously [26, 27]. RNA samples obtained from the 366 cancer samples and 100 normal lung tissues in the discovery and validation cohorts, were examined with the lncRNA microarray. Briefly, each probe was mixed with printing buffer to a final concentration of $40 \mu \mathrm{mol} / \mathrm{L}$ and printed in duplicate on the cleaned glass slides $(75 \times 25 \mathrm{~mm})$. The total RNA $2.0 \mu \mathrm{g}$ was labeled with $100 \mathrm{nmol} / \mathrm{L}$ of Cy5-dUTP (Enzo Life Sciences, New York, USA) in reverse transcription. Then the mixture of labeled RNA sample and $1 \times$ hybridization solution was hybridized onto the microarray for $12-18 \mathrm{~h}$ at $45{ }^{\circ} \mathrm{C}$. After hybridization, the slides were washed in $1 \times$ $\mathrm{SSC} / 1 \% \mathrm{SDS}$ for $10 \mathrm{~min}$ at $45{ }^{\circ} \mathrm{C}$, followed by sequential washing in 2 cycles of $0.5 \times \mathrm{SSC} / 0.1 \%$ SDS, 2 cycles of $0.2 \times \mathrm{SSC}$ and 1 cycle of purified water for $1 \mathrm{~min}$ at room temperature, respectively, and then dried in a special small centrifuge and scanned using the InnoScan 700A Scanner (Innopsys Inc, France).

\section{Microarray data processing}

The raw microarray data were first processed by subtracting the background signals and then normalized with the quantile method and a log transformation. The logtransformed data were deposited in the GEO database (National Center for Biotechnology Information website), under GEO Accession number GSE143018 (https://www. ncbi.nlm.nih.gov/geo/query/acc.cgi?acc=GSE143018).

To identify differentially expressed lncRNAs between lung cancer tissues and paired normal lung tissues, the Significance Analysis of Microarrays (SAM) program was employed to identify lncRNAs with a fold-change of $>1.25$, a $P$-value of $<0.01$, and a false-discovery rate (FDR) of $<0.01$ ( $t$ test). Hierarchical-clustering analysis (for classifying the samples in the discovery cohort) was performed using the average-linkage method and uncentered Pearson's correlation coefficients in MEV software, version 4.2.

\section{Statistical analysis}

Correlations between the 4-lncRNA prognostic signature and clinical characteristics were assessed by Fisher's exact test and the $X^{2}$ test, using SPSS software, version 23.0. The prognostic accuracies of the 4-IncRNA signature, the TNM staging system, and the combined-risk model were compared with receiver operating characteristic (ROC) curves, which were generated using MedCalc software, version 11.4.2. The OS and DFS of patients were assessed using the Kaplan-Meier method, and the corresponding graphs were generated using GraphPad Prism software, version 8.0.

The impacts of the lncRNA-expression level and clinical characteristics on DFS and OS were determined using univariate and multivariate Cox-regression models. By employing the risk-score method reported previously $[28,29], 15$ IncRNAs were incorporated into different combinations to construct a signature and tested by survival analysis, and the lncRNAs were gradually subtracted from the combinations to obtain a final 4-lncRNA signature with the greatest prognostic value.

\section{Results \\ Detection of IncRNA-expression profiles in NSCLC tissues from the discovery cohort, using a custom microarray}

The 366 patients with NSCLC from Sun Yat-Sen University Cancer Center in Southern China were randomly divided into a discovery cohort and a validation cohort. The clinical characteristics of these patients are shown in Table 1. We first detected the lncRNA-expression profiles in 194 NSCLC samples and 100 matched normal lung tissues in the discovery cohort, using an in-house generated lncRNA microarray containing 2412 human lncRNA probes. After subtracting the background signals, and normalizing and log-transforming the microarray data, we analyzed the lncRNA-expression profiles with the SAM program and Student's $t$ test, and identified 305 differentially expressed lncRNAs between the NSCLC tissues and adjacent normal lung tissues (FDR $=0$ and fold-change $>1.25$ ), of which 138 lncRNAs were upregulated and 167 were down-regulated in the NSCLC tissues (Additional file 1: Fig. S1 and Table S2). The log-transformed microarray data were submitted and deposited in the GEO database.

To confirm the reliability and repeatability of the microarray results, 5 out of 15 prognostic lncRNAs were selected for qRT-PCR analysis with 30 pairs of samples that were randomly selected from the discovery cohort. Of these 5 lncRNAs, 2 (NEAT1 and XLOC_009261) were up-regulated and 3 (XLOC_005302, XLOC_001306, and lnc-GAN1) were down-regulated in the lung cancer tissues, compared with that in the normal lung tissues. The expression-level ratios of the 5 lncRNAs in cancer tissues versus adjacent tissues detected by qRT-PCR were consistent with the microarray results (Fig. 1a) and significant correlations were found between the qRT-PCR and microarray data for the 5 lncRNAs (Fig. 1b-f). These results reveal that the lncRNA-expression levels detected with the lncRNA microarray are reliable and reproducible, which can be used for further analysis. 


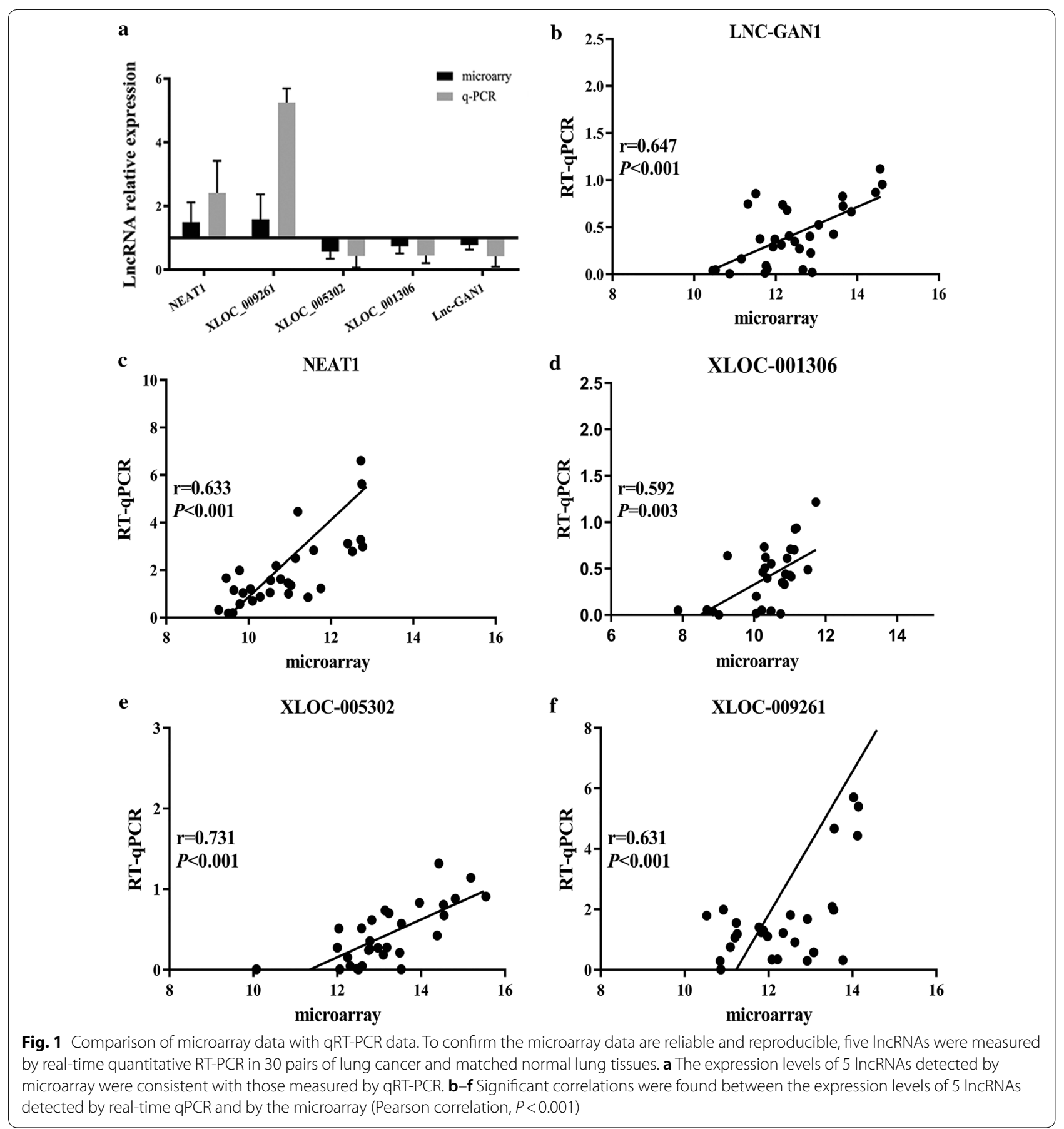

Identification of a 4-IncRNA prognostic signature for NSCLC patients in the discovery cohort

To elucidate the prognostic significance of lncRNAs in NSCLC, we conducted univariate Cox regression analysis on all 305 differentially expressed lncRNAs in the discovery cohort. Based on the threshold of $P$-value $<0.05,15$ lncRNAs were significantly associated with OS in the NSCLC patients (Table 2), of which 6 lncRNAs were risky and 9 lncRNAs were protective.

To determine an optimal lncRNA combination (signature) for predicting the survival outcomes of patients with NSCLC, we employed the 15 lncRNAs associated with survival to establish a prognostic signature with a risk-score method, as previously reported [28, 29]. Using this method, we established a 4-IncRNA signature with 
Table 2 Summary of 15 IncRNAs associated with overall survival of NSCLC patients in the discovery cohort

\begin{tabular}{llllll}
\hline No & LncRNA & Weight & P value & HR (95\% Cl) & Putative function \\
\hline 1 & BF768381 & 0.168 & 0.048 & $1.183(1.001-1.390)$ & High-risk \\
2 & DD3 & 0.212 & 0.035 & $1.236(1.015-1.500)$ & High-risk \\
3 & BF944729 & 0.228 & 0.045 & $1.255(1.005-1.560)$ & High-risk \\
4 & SRG1 & 0.439 & 0.006 & $1.552(1.136-2.120)$ & High-risk \\
5 & NEAT1 & 0.412 & 0.003 & $1.510(1.154-1.970)$ & High-risk \\
6 & Zeb2NAT & 0.344 & 0.019 & $1.411(1.057-1.880)$ & High-risk \\
7 & ASLNC03555 & -0.574 & 0.025 & $0.563(0.342-0.920)$ & Protective \\
8 & ASLNC09137 & -0.488 & 0.025 & $0.614(0.401-0.940)$ & Protective \\
9 & GSO_1539211_377 & -0.578 & 0.039 & $0.561(0.324-0.970)$ & Protective \\
10 & GSO_1539832_035 & -0.486 & 0.041 & $0.615(0.386-0.980)$ & Protective \\
11 & Lnc-GAN1 & -0.349 & 0.048 & $0.705(0.499-0.990)$ & Protective \\
12 & GSO_1539211_480 & -0.446 & 0.007 & $0.640(0.463-0.880)$ & Protective \\
13 & ASLNC11245 & -1.269 & 0.000 & $0.281(0.143-0.550)$ & Protective \\
14 & BF375442 & -0.348 & 0.026 & $0.706(0.520-0.950)$ & Protective \\
15 & GSO_1539832_023 & -0.503 & 0.010 & $0.605(0.412-0.880)$ & Protective \\
\hline
\end{tabular}

the highest prognostic power, consisting of NEAT1, lncGAN1, ASLNC11245, and GSO_1539832_023. Based on the expression levels of the 4 lncRNAs (measured by microarray analysis and weighted by their corresponding regression coefficients derived from univariate Coxregression analysis), the risk scores were calculated as follows:

$$
\begin{aligned}
\text { Risk score }= & (0.412 \times \text { NEAT1 level }) \\
& +(-0.349 \times \text { lnc }- \text { GAN1 level }) \\
& +(-1.269 \times \text { ASLNC11245 level }) \\
& +(-0.503 \times \text { GSO_1539832_023 level }) .
\end{aligned}
$$

The risk-score formula was used to calculate risk scores for each patient, who were divided into high- and lowrisk groups according to median risk score. KaplanMeier-survival analysis showed that patients in the high-risk group had remarkably lower OS and DFS rates than those in the low-risk group (Fig. 2a), implying that this prognostic signature is potentially highly effective for predicting the survival of patients with NSCLC.

\section{Validation of the 4-IncRNA prognostic signature in patients with NSCLC from a multicenter registry}

To verify the prognostic value of the 4-lncRNA signature identified in the discovery cohort, we attempted to validate it with NSCLC patients from two different geographical locations, where one cohort was used as an internal validation cohort, and the other was used as an independent validation cohort. First, we tested the 4-IncRNA signature with the internal validation cohort ( $\mathrm{n}=172$ NSCLC samples) acquired from the same center as the discovery cohort in southern China. The NSCLC samples in the internal validation cohort were analyzed using the same lncRNA microarray and risk-score formula that was used for the discovery cohort. Based on the risk scores, patients in the internal validation cohort were classified into high-risk and low-risk groups. Survival analysis showed that patients in the high-risk group had significantly lower OS and DFS rates than those in the low-risk group (Fig. 2b), which was consistent with the results obtained in the discovery cohort.

Second, we tested the 4-IncRNA prognostic signature with another 73 NSCLC samples (as an independent validation cohort) obtained from another medical center in southwestern China and detected the expression of the 4 lncRNAs using qRT-PCR. Then, univariate Coxregression analysis was performed on the 4 lncRNAs, and a risk-score formula was constructed with the same method used in the discovery cohort:

$$
\begin{aligned}
\text { Risk score }= & (0.297 \times \text { NEAT1 level }) \\
& +(-0.259 \times \text { lnc }- \text { GAN1 level }) \\
& +(-0.706 \times \text { ASLNC11245 level }) \\
& +(-0.153 \times \text { GSO_1539832_023 level }) .
\end{aligned}
$$

We calculated the risk score for each patient with the new formula (shown immediately above) in the independent validation cohort. By applying the median risk score as the cutoff point, patients were categorized into high- and low-risk groups. As shown in Fig. 2c, the OS and DFS rates of patients with NSCLC in the high-risk group were significantly lower than those in the low-risk group, which was in concordance with the results obtained from the discovery and internal validation cohorts. The above results demonstrated that the 


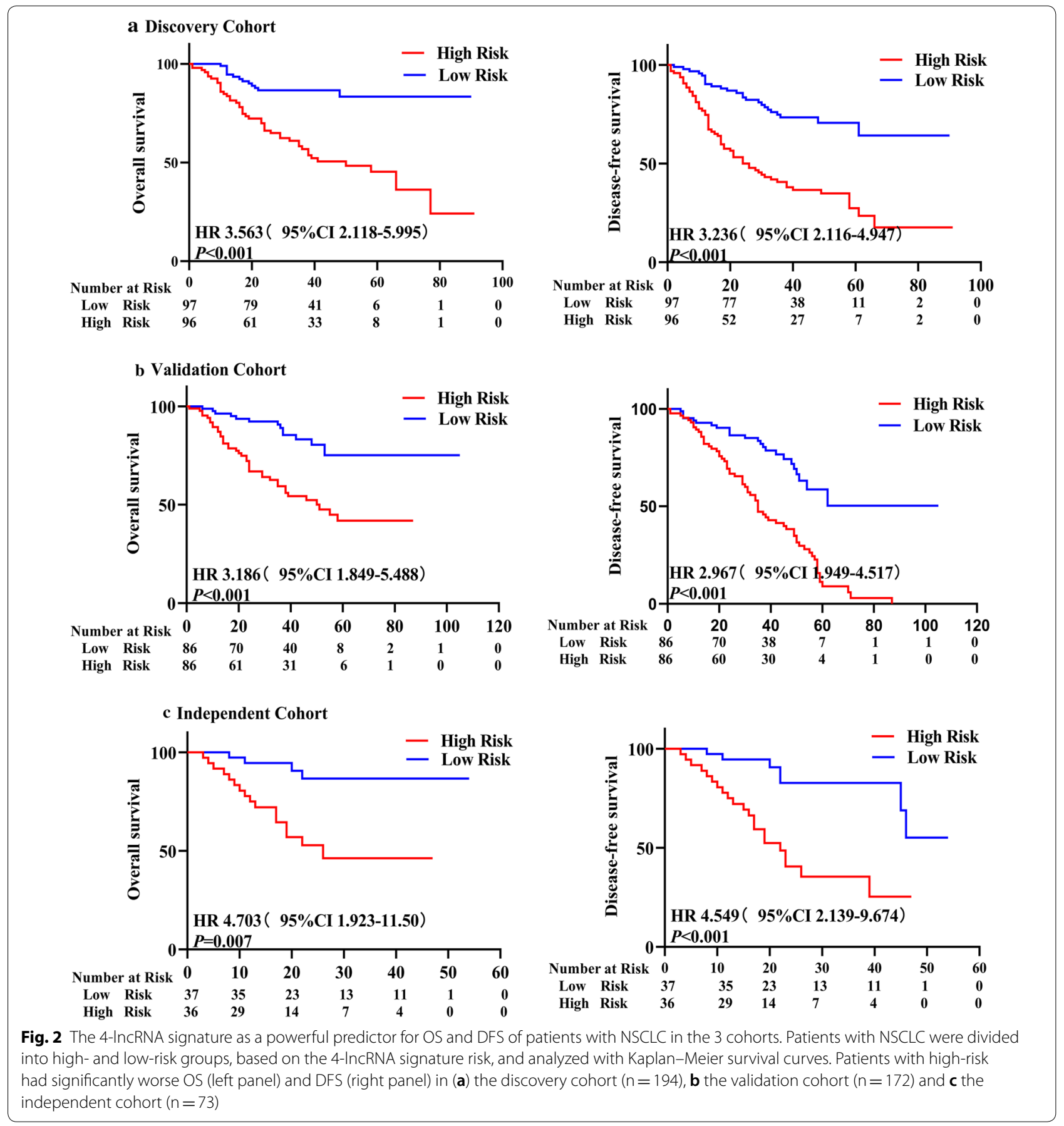

4-lncRNA signature is correlated significantly with the prognosis of patients with NSCLC from a multicenter cohort in different geographical regions, suggesting that the 4-lncRNA signature is a new and powerful prognostic biomarker for patients with NSCLC from different regions of China.
The 4-IncRNA prognostic signature was independent of the TNM staging system

To gain deeper insight into the clinical significance of the 4-lncRNA signature, we first conducted a correlation analysis between the signature and any associated clinical characteristics. The results showed that the 4-lncRNA signature did not correlate with any 
Table 3 The relationship between 4-IncRNA signature and Clinical characteristics in the three NSCLC patient cohorts

\begin{tabular}{|c|c|c|c|c|c|c|c|c|c|}
\hline \multirow[t]{2}{*}{ Characteristics } & \multicolumn{3}{|c|}{ Discovery cohort $(\mathrm{N}=194)$} & \multicolumn{3}{|c|}{ Validation cohort $(\mathrm{N}=172)$} & \multicolumn{3}{|c|}{ Independent cohort $(\mathrm{N}=73)$} \\
\hline & $\begin{array}{l}\text { Low-risk } \\
\text { n (\%) }\end{array}$ & $\begin{array}{l}\text { High-risk } \\
\text { n (\%) }\end{array}$ & $P$ value & $\begin{array}{l}\text { Low-risk } \\
\text { n (\%) }\end{array}$ & $\begin{array}{l}\text { High-risk } \\
\text { n (\%) }\end{array}$ & $P$ value & $\begin{array}{l}\text { Low-risk } \\
\text { n (\%) }\end{array}$ & $\begin{array}{l}\text { High-risk } \\
\text { n (\%) }\end{array}$ & $P$ value \\
\hline \multicolumn{10}{|l|}{ Age } \\
\hline$\geq 60$ & $52(53.6)$ & $49(50.5)$ & 0.706 & $49(57.0)$ & $46(53.5)$ & 0.816 & $19(51.4)$ & $21(58.3)$ & 0.493 \\
\hline$<60$ & $45(46.4)$ & $48(49.5)$ & & $37(43.0)$ & $40(46.5)$ & & $18(48.6)$ & $15(41.7)$ & \\
\hline \multicolumn{10}{|l|}{ Gender } \\
\hline Male & $82(84.5)$ & $72(74.2)$ & 0.269 & $67(77.9)$ & $69(80.2)$ & 0.374 & $29(78.4)$ & $23(63.9)$ & 0.290 \\
\hline Female & $15(15.5)$ & $25(25.8)$ & & $19(22.1)$ & $17(19.8)$ & & $8(21.6)$ & $13(36.1)$ & \\
\hline \multicolumn{10}{|l|}{ TNM stage } \\
\hline I & $46(47.4)$ & $41(42.3)$ & 0.637 & $39(45.3)$ & $35(40.7)$ & 0.702 & $13(35.1)$ & $10(27.8)$ & 0.518 \\
\hline$\|$ & $11(11.3)$ & $21(21.6)$ & & $18(21.0)$ & $16(18.6)$ & & $8(21.6)$ & $12(33.3)$ & \\
\hline III & $40(41.2)$ & $35(36.1)$ & & $29(33.7)$ & $35(40.7)$ & & $16(43.2)$ & $14(38.9)$ & \\
\hline \multicolumn{10}{|l|}{ Histological type } \\
\hline ADC & $55(56.7)$ & $40(41.2)$ & 0.304 & $39(45.3)$ & $50(58.1)$ & 0.297 & $25(67.6)$ & $22(61.1)$ & 0.451 \\
\hline SCC & $39(40.2)$ & $49(50.5)$ & & $40(46.5)$ & $36(41.9)$ & & $12(32.4)$ & $14(38.9)$ & \\
\hline $\mathrm{ADC} / \mathrm{SCC}$ & $3(3.1)$ & $8(8.3)$ & & $7(8.2)$ & $0(0.0)$ & & $0(0.0)$ & $0(0.0)$ & \\
\hline \multicolumn{10}{|l|}{ Tumor size (cm) } \\
\hline$<5$ & $59(60.8)$ & $49(50.5)$ & 0.332 & $46(53.5)$ & $51(59.3)$ & 0.573 & $13(35.1)$ & $18(50.0)$ & 0.197 \\
\hline$\geq 5$ & $38(39.2)$ & $48(49.5)$ & & $40(46.5)$ & $35(40.7)$ & & $24(64.9)$ & $18(50.0)$ & \\
\hline \multicolumn{10}{|l|}{ Differentiation } \\
\hline Well/moderate & $58(59.8)$ & $68(70.1)$ & 0.402 & $44(51.2)$ & $61(70.9)$ & 0.203 & $19(51.4)$ & $24(66.7)$ & 0.310 \\
\hline Poor & $39(40.2)$ & $29(29.9)$ & & $42(48.8)$ & $25(29.1)$ & & $18(48.6)$ & $12(33.3)$ & \\
\hline \multicolumn{10}{|l|}{ Lymph metastasis } \\
\hline No & $47(48.5)$ & $58(59.8)$ & 0.257 & $39(45.3)$ & $42(48.8)$ & 0.574 & $21(56.8)$ & $24(66.7)$ & 0.297 \\
\hline Yes & $50(51.5)$ & $39(40.2)$ & & $47(54.7)$ & $44(51.2)$ & & $16(43.2)$ & $12(33.3)$ & \\
\hline \multicolumn{10}{|l|}{ Smoking history } \\
\hline No & $36(37.1)$ & $43(44.3)$ & 0.503 & $29(33.7)$ & $33(38.4)$ & 0.692 & $15(40.5)$ & $18(50.0)$ & 0.307 \\
\hline Yes & $61(62.9)$ & $54(55.7)$ & & $57(66.3)$ & $53(61.6)$ & & $22(59.5)$ & $18(50.0)$ & \\
\hline \multicolumn{10}{|l|}{ Fam. cancer hist. } \\
\hline No & 84 (86.6) & 77 (79.3) & 0.396 & $73(75.3)$ & 78 (90.7) & 0.417 & $36(97.3)$ & 35 (97.2) & 0.664 \\
\hline Yes & $13(13.4)$ & $20(20.7)$ & & $13(13.4)$ & $8(9.3)$ & & $1(2.7)$ & $1(2.8)$ & \\
\hline
\end{tabular}

Fam. cancer hist. Family cancer history

clinical characteristics in the 3 cohorts (Table 3), implying that the signature was independent of the clinical characteristics. Then, we carried out a univariate Coxregression analysis of the signature and clinical characteristics. The results revealed that only the 4-lncRNA signature and TNM stage were associated with the OS (Table 4) and DFS (Table 5) rates of patients with NSCLC in all the 3 cohorts, providing further evidence that the 4-IncRNA signature is a useful prognostic indicator. Finally, we performed a multivariate Coxregression analysis on the 4-lncRNA signature and all clinical characteristics. After adjustment for other clinicopathological variables, both the 4-lncRNA signature and the TNM stage correlated significantly with OS and DFS rates of patients in all the 3 cohorts, whereas other factors did not (Table 6). To further confirm the utility of the 4-lncRNA signature as an independent predictive factor for survival, we performed a stratified analysis of patients at three different TNM stages with the 4-IncRNA prognostic signature. Patients in the same TNM stage (stage I, II, or III) were divided into high- or low-risk subgroups, based on the risk scores generated with the 4-lncRNA prognostic signature. The results showed that NSCLC patients with high-risk scores generally had significantly lower OS and DFS rates than those with low-risk scores (Fig. 3) in stage I, II, or III, indicating that the prognostic 4-lncRNA signature is performed independently of the TNM staging system. Collectively, these results indicated that the 4-lncRNA signature is a powerful and independent prognostic indicator for patients with NSCLC. 
Table 4 Univariate Cox regression analysis of the impact of the IncRNA signature and other clinicopathological features on OS in the three NSCLC patient cohorts

\begin{tabular}{|c|c|c|c|c|c|c|}
\hline \multirow[t]{2}{*}{ Parameters } & \multicolumn{2}{|l|}{ Training cohort } & \multicolumn{2}{|l|}{ Validation cohort } & \multicolumn{2}{|l|}{ Independent cohort } \\
\hline & Hazard ratio $(95 \% \mathrm{Cl})$ & $P$ value & Hazard ratio $(95 \% \mathrm{Cl})$ & $P$ value & Hazard ratio $(95 \% \mathrm{Cl})$ & $P$ value \\
\hline \multicolumn{7}{|l|}{ Signature } \\
\hline (High vs low) & $3.20(0.58-1.65)$ & $<0.001$ & $2.84(1.59-5.07)$ & $<0.001$ & $2.84(1.59-5.07)$ & 0.009 \\
\hline \multicolumn{7}{|l|}{ Age } \\
\hline$(\geq 60$ vs $<60)$ & $1.24(0.73-2.09)$ & 0.417 & $1.13(0.67-1.91)$ & 0.330 & $0.88(0.36-2.13)$ & 0.782 \\
\hline \multicolumn{7}{|l|}{ Gender } \\
\hline (Male vs female) & $0.86(0.48-1.52)$ & 0.619 & $1.24(0.63-2.41)$ & 0.050 & $0.98(0.37-2.57)$ & 0.978 \\
\hline \multicolumn{7}{|l|}{ TNM stages } \\
\hline (III vs II vs I) & $1.67(1.28-2.19)$ & $<0.001$ & $1.70(1.30-2.23)$ & 0.001 & $1.74(1.04-2.89)$ & 0.031 \\
\hline \multicolumn{7}{|l|}{ Histological type } \\
\hline (ADC vs SCC) & $1.30(0.74-2.29)$ & 0.346 & $1.39(0.82-2.36)$ & 0.589 & $0.53(0.15-1.83)$ & 0.320 \\
\hline \multicolumn{7}{|l|}{ Tumor size } \\
\hline$(\geq 5 \mathrm{~cm}$ vs $<5 \mathrm{~cm})$ & $1.17(0.69-1.98)$ & 0.545 & $1.15(0.68-1.95)$ & 0.017 & $3.00(1.00-9.00)$ & 0.048 \\
\hline \multicolumn{7}{|l|}{ Differentiation } \\
\hline (Poor vs well/mod) & $0.98(0.58-1.65)$ & 0.951 & $1.43(0.85-2.42)$ & 0.079 & $1.80(0.74-4.32)$ & 0.188 \\
\hline \multicolumn{7}{|l|}{ Lymph metastasis } \\
\hline (Yes vs no) & $1.44(0.86-2.43)$ & 0.163 & $0.73(0.43-1.24)$ & 0.025 & $1.38(0.46-4.14)$ & 0.561 \\
\hline \multicolumn{7}{|l|}{ Smoking history } \\
\hline (Yes vs no) & $0.91(0.54-1.54)$ & 0.736 & $1.63(0.92-2.91)$ & 0.024 & $1.11(0.46-2.68)$ & 0.812 \\
\hline \multicolumn{7}{|l|}{ Fam. cancer hist. } \\
\hline (Yes vs no) & $1.04(0.52-2.06)$ & 0.899 & $1.18(0.58-2.42)$ & 0.580 & $0.47(2.97-7.64)$ & 0.618 \\
\hline
\end{tabular}

Italic $P$ values represent the statistic significance

Fam. cancer hist. Family cancer history

The 4-IncRNA signature provids additional prognostic information to the TNM staging system in patients with NSCLC

In clinical practice, the traditional TNM staging system is the main assessment used to predict the survival of patients with NSCLC and to determine the treatment strategy. However, the TNM staging system is mainly based on anatomical information and does not include factors related to the tumor biology. Therefore, the TNM system is insufficient for predicting survival outcomes in patients with NSCLC [30]. For example, Kaplan-Meiersurvival analysis of the 3 cohorts in this study showed that the TNM stage system did not effectively determine the prognosis of NSCLC patients at different stages, especially in stages I and II (Fig. 4). To improve the ability of the TNM staging system to predict patient survival, we established a new risk-score model by combining the risk scores of the 4-lncRNA signature and the TNM staging system: low- and high-risk signatures were scored as 0 and 1 , respectively, and stage I, II, and III NSCLC were scored as 1, 2, and 3, respectively. Patients with combined scores of $1,2-3$, or 4 were classified as low-, mediumor high-risk patients, respectively. Then we performed Kaplan-Meier-survival analysis of the patients with different combined risks in the 3 cohorts. The results revealed significant differences in OS and DFS rates between patients with low, medium, or high risk in the discovery cohort (Fig. 5a), and these results were confirmed in the internal validation and independent validation cohorts (Fig. 5b, c).

Next, receiver operating characteristic (ROC) analysis was performed to compare the accuracy of the TNM staging system and the combined-risk model. ROC analysis showed that the combined-risk model achieved a significantly higher predictive accuracy for OS $(\mathrm{AUC}=0.726$ vs. 0.644$)$ and $\mathrm{DFS}(\mathrm{AUC}=0.723$ vs. 0.641$)$ than that achieved by the TNM staging system in the discovery cohort (Fig. 6a). Similar results were observed in the internal validation cohort and the independent validation cohort (Fig. 6b, c). These results demonstrated that the 4-lncRNA signature can provide additional prognostic information and improve the prognostic power of the TNM staging system.

\section{Discussion}

LncRNAs are widely dysregulated in various cancers and participate in a diverse range of associated biological functions. Numerous aberrant lncRNAs have been 
Table 5 Univariate Cox regression analysis of the impact of IncRNA signature and other clinicopathological features on DFS in the three NSCLC patient cohorts

\begin{tabular}{|c|c|c|c|c|c|c|}
\hline \multirow[t]{2}{*}{ Parameters } & \multicolumn{2}{|l|}{ Training group } & \multicolumn{2}{|l|}{ Validation group } & \multicolumn{2}{|l|}{ Independent group } \\
\hline & Hazard ratio $(95 \% \mathrm{Cl})$ & $P$ value & Hazard ratio $(95 \% \mathrm{Cl})$ & $P$ value & Hazard ratio $(95 \% \mathrm{Cl})$ & $P$ value \\
\hline \multicolumn{7}{|l|}{ Signature } \\
\hline (High vs low) & $2.61(1.50-4.56)$ & $<0.001$ & $3.21(1.80-5.71)$ & $<0.001$ & $2.18(1.10-4.34)$ & 0.025 \\
\hline \multicolumn{7}{|l|}{ Age } \\
\hline$(\geq 60$ vs $<60)$ & $1.30(0.76-2.21)$ & 0.330 & $1.30(0.76-2.21)$ & 0.510 & $1.19(0.60-2.35)$ & 0.599 \\
\hline \multicolumn{7}{|l|}{ Gender } \\
\hline (Male vs female) & $0.57(0.33-1.00)$ & 0.050 & $0.97(0.53-1.78)$ & 0.945 & $0.77(0.37-1.60)$ & 0.496 \\
\hline \multicolumn{7}{|l|}{ TNM stages } \\
\hline (III vs II vs I) & $1.55(1.18-2.04)$ & 0.001 & $1.70(1.29-2.25)$ & $<0.001$ & $1.46(1.00-2.12)$ & 0.045 \\
\hline \multicolumn{7}{|l|}{ Histological type } \\
\hline (ADC vs SCC) & $0.83(0.44-1.59)$ & 0.589 & $1.48(0.88-2.49)$ & 0.133 & $1.02(0.45-2.29)$ & 0.954 \\
\hline \multicolumn{7}{|l|}{ Tumor size } \\
\hline$(\geq 5 \mathrm{~cm}$ vs $<5 \mathrm{~cm})$ & $1.89(1.12-3.22)$ & 0.017 & $1.57(0.94-2.61)$ & 0.082 & $1.92(0.92-4.03)$ & 0.081 \\
\hline \multicolumn{7}{|l|}{ Differentiation } \\
\hline (Poor vs well/moderate) & $0.62(0.36-1.05)$ & 0.079 & $1.22(0.73-2.04)$ & 0.427 & $1.29(0.65-2.57)$ & 0.453 \\
\hline \multicolumn{7}{|l|}{ Lymph metastasis } \\
\hline (Yes vs no) & $1.82(1.07-3.10)$ & 0.025 & $1.72(1.01-2.91)$ & 0.042 & $2.13(0.87-5.23)$ & 0.095 \\
\hline \multicolumn{7}{|l|}{ Smoking history } \\
\hline (Yes vs no) & $0.54(0.32-0.92)$ & 0.024 & $1.15(0.68-1.95)$ & 0.586 & $1.00(0.51-1.97)$ & 0.989 \\
\hline \multicolumn{7}{|l|}{ Fam. cancer hist. } \\
\hline (Yes vs no) & $0.80(0.38-1.71)$ & 0.580 & $0.69(0.31-1.53)$ & 0.369 & $1.23(0.16-9.12)$ & 0.834 \\
\hline
\end{tabular}

Italic $P$ values represent the statistic significance

Fam. cancer hist. Family cancer history

detected as hallmarks of cancers and can potentially be used for diagnosis, prognosis, and targeted therapy in cancer. Some investigators have discovered lncRNA profiles and lncRNA signatures in NSCLC by mining data from the GEO and TCGA databases. For example, Zhou et al [31] analyzed the lncRNA-expression profiles of 603 patients from 3 independent NSCLC cohorts in the GEO database and developed a riskscore model based on the expression of 8 lncRNAs, which were significantly associated with OS in patients with NSCLC. Lin et al. [10] identified a 7-lncRNA signature for predicting the OS of patients with NSCLC after combining lncRNA profiles from 4 GEO datasets and validated the signature in 2 independent datasets (TCGA and GSE31210). Recently, He et al. [32] proposed a novel 8-gene signature as a prognostic indicator for patients with early-stage NSCLC after analyzing data from the GEO and TCGA projects. However, the abovementioned prognostic signatures generated by data mining have not been confirmed in patients with NSCLC in a prospective multicenter study. Therefore, the clinical application of prognostic lncRNA biomarkers in NSCLC remains very limited to date. Here, we report the first lncRNA-expression profiling (as determined by microarray analysis) of a large cohort of patients with NSCLC and the identification of an effective prognostic 4-lncRNA signature.

In this study, we identified 305 aberrantly expressed lncRNAs in 104 NSCLC tissues when compared with those in matched normal tissues in the discovery cohort, using a custom lncRNA microarray containing 2412 probes. Notably, we identified a novel 4-lncRNA prognostic signature for patients with NSCLC in the discovery cohort. Kaplan-Meier-survival analysis demonstrated the effective prognostic performance of the 4-lncRNA signature in all the 3 cohorts. Multivariate Cox-regression analysis identified the 4-lncRNA signature as an independent prognostic factor for patients with NSCLC in all the cohorts.

Although TNM staging is widely accepted for disease prognosis and guiding treatment decisions for most solid cancers (including NSCLC), at present, the TNM staging system has critical limitations and insufficiencies in clinical practice, due to intra-tumoral molecular and genetic heterogeneities among patients with lung cancer. The clinical outcomes of lung cancer patients with similar clinical and pathological features are often quite different after receiving similar treatments. Therefore, 
Table 6 Multivariate Cox regression analysis of the impact of IncRNA signature and clinicopathological features on OS and DFS in the three NSCLC patient cohorts

\begin{tabular}{|c|c|c|c|c|c|}
\hline \multirow[t]{2}{*}{ Dataset } & \multirow[t]{2}{*}{ Parameters } & \multicolumn{2}{|l|}{ Overall survival } & \multicolumn{2}{|l|}{ Disease-free survival } \\
\hline & & Hazard ratio $(95 \% \mathrm{Cl})$ & $P$ value & Hazard ratio $(95 \% \mathrm{Cl})$ & $P$ value \\
\hline \multirow[t]{11}{*}{ Training } & Signature & $3.18(1.62-6.23)$ & 0.001 & $2.17(1.35-3.47)$ & 0.001 \\
\hline & Age & $1.07(0.78-1.45)$ & 0.401 & $1.03(0.76-1.40)$ & 0.845 \\
\hline & Gender & $1.61(0.57-4.51)$ & 0.365 & $1.42(0.54-3.73)$ & 0.474 \\
\hline & TNM stages & $1.61(1.09-2.15)$ & 0.008 & $1.47(1.06-2.05)$ & 0.022 \\
\hline & Histological types & $0.99(0.61-1.61)$ & 0.965 & $0.94(0.58-1.51)$ & 0.783 \\
\hline & Tumor sizes & $0.91(0.47-1.73)$ & 0.767 & $0.86(0.45-1.64)$ & 0.657 \\
\hline & Differentiation & $1.18(0.78-1.78)$ & 0.43 & $1.12(0.75-1.68)$ & 0.587 \\
\hline & Pleural invasion & $1.60(0.85-3.01)$ & 0.147 & $1.79(0.96-3.35)$ & 0.068 \\
\hline & Vascular invasion & $2.17(0.75-6.28)$ & 0.154 & $1.86(0.65-5.34)$ & 0.248 \\
\hline & Smoking history & $2.94(1.15-7.50)$ & 0.024 & $2.60(1.09-6.24)$ & 0.032 \\
\hline & Fam. cancer hist. & $0.58(0.25-1.37)$ & 0.218 & $0.53(0.23-1.25)$ & 0.146 \\
\hline \multirow[t]{11}{*}{ Validation } & Signature & $2.41(1.47-3.97)$ & 0.001 & $2.49(1.53-4.05)$ & $<0.001$ \\
\hline & Age & $1.14(0.87-1.49)$ & 0.359 & $1.13(0.87-1.48)$ & 0.349 \\
\hline & Gender & $0.64(0.32-1.27)$ & 0.201 & $0.79(0.41-1.55)$ & 0.498 \\
\hline & TNM stages & $1.40(1.03-1.91)$ & 0.031 & $1.40(1.04-1.88)$ & 0.026 \\
\hline & Histological types & $0.92(0.62-1.38)$ & 0.697 & $0.94(0.63-1.4)$ & 0.763 \\
\hline & Tumor sizes & $1.41(0.80-2.49)$ & 0.240 & $1.27(0.73-2.23)$ & 0.402 \\
\hline & Differentiation & $0.89(0.59-1.32)$ & 0.552 & $0.88(0.60-1.31)$ & 0.537 \\
\hline & Pleural invasion & $1.42(0.85-2.39)$ & 0.185 & $1.51(0.90-2.52)$ & 0.116 \\
\hline & Vascular invasion & $5.40(1.73-16.8)$ & 0.004 & $4.91(1.59-15.17)$ & 0.006 \\
\hline & Smoking history & $0.54(0.28-1.04)$ & 0.064 & $0.52(0.27-1.00)$ & 0.050 \\
\hline & Fam. cancer hist. & $1.22(0.66-2.28)$ & 0.521 & $1.48(0.81-2.70)$ & 0.206 \\
\hline \multirow[t]{9}{*}{ Independent } & Signature & $1.88(1.15-3.08)$ & 0.012 & $1.80(1.14-2.84)$ & 0.012 \\
\hline & Age & $1.00(0.70-1.42)$ & 0.988 & $1.19(0.86-1.66)$ & 0.294 \\
\hline & Gender & $0.80(0.46-1.40)$ & 0.430 & $0.70(0.42-1.18)$ & 0.183 \\
\hline & TNM stages & $1.80(1.28-2.54)$ & 0.001 & $1.69(1.24-2.30)$ & 0.001 \\
\hline & Histological types & $1.26(0.74-2.13)$ & 0.395 & $1.12(0.69-1.84)$ & 0.640 \\
\hline & Tumor sizes & $1.78(1.06-2.97)$ & 0.028 & $1.92(1.19-3.09)$ & 0.008 \\
\hline & Differentiation & $1.66(1.03-2.66)$ & 0.037 & $1.81(1.16-2.83)$ & 0.009 \\
\hline & Pleural invasion & $1.26(0.68-2.33)$ & 0.466 & $1.59(0.87-2.91)$ & 0.130 \\
\hline & Vascular invasion & $1.75(0.39-7.92)$ & 0.468 & $2.81(0.79-9.98)$ & 0.110 \\
\hline
\end{tabular}

Italic $P$ values represent the statistic significance

Fam. cancer hist. Family cancer history

more personalized molecular markers are urgently needed to assist doctors in clinical practice. In our stratified analysis, the 4-IncRNA signature showed prognostic value for patients at the same stage. Moreover, a riskscore model derived by combining the 4-InRNA signature and the TNM stage was developed. The combined risk score showed superior performance in predicting OS and DFS rates in all the 3 cohorts, compared with TNM staging system, based on Kaplan-Meier-survival analysis and ROC analysis. Our findings demonstrated that the 4-lncRNA signature can significantly improve the prognostic accuracy of TNM staging and that it can potentially be considered as a marker for risk assessment among patients with NSCLC. Combining the 4-lncRNA signature with the traditional TNM staging parameters might serve as a powerful prognostic approach for patients with NSCLC and can potentially facilitate the selection of patients with more aggressive disease who would benefit from adjuvant therapy.

Among the 4 lncRNAs in the lncRNA signature, only NEAT1 has been linked with cancer. NEAT1 is aberrantly expressed in many malignant human diseases (including lung cancer) and functions as an oncogene. Higher NEAT1 expression correlated with 


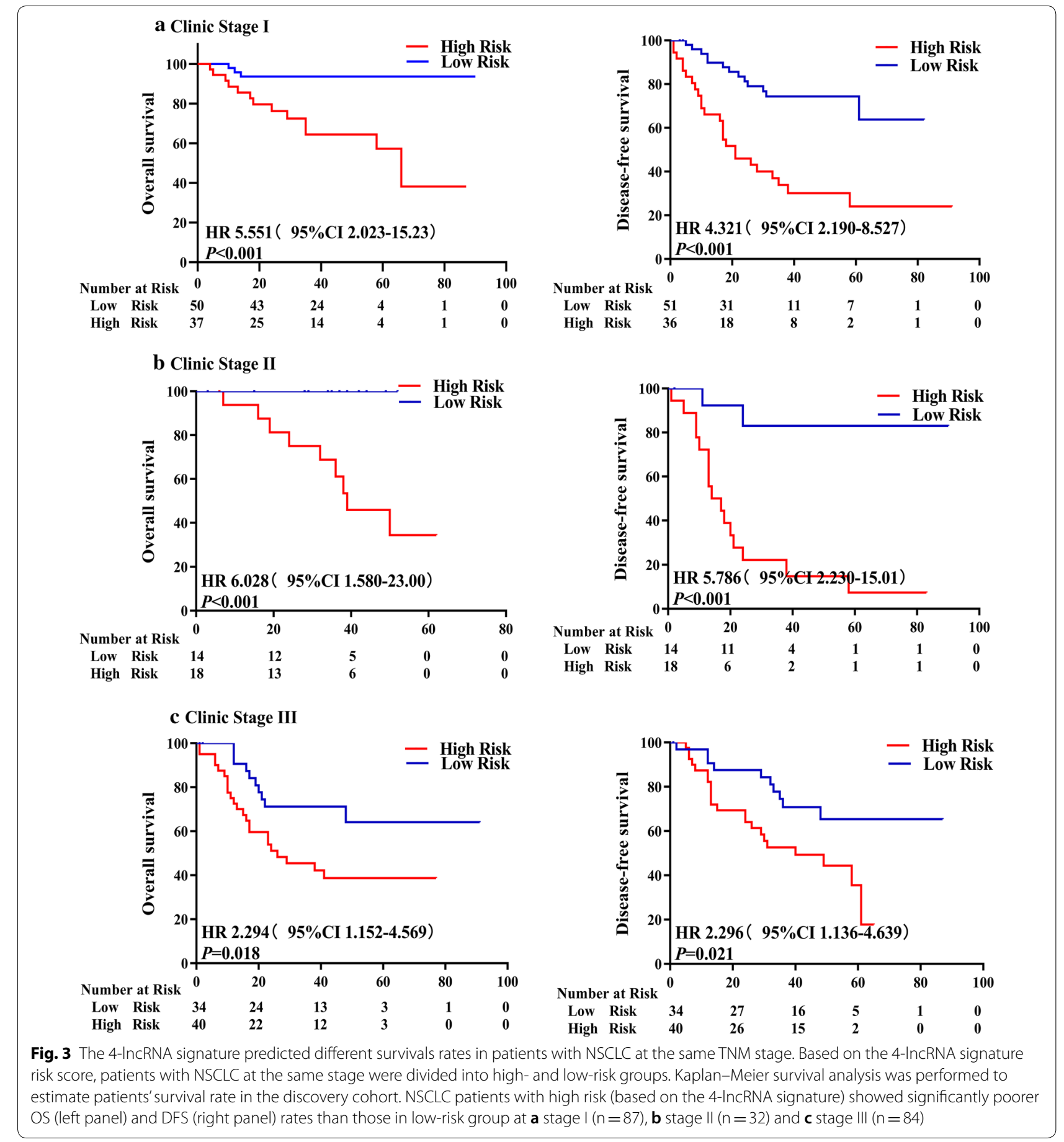

an advanced TNM stage and lymphatic metastasis in patients with NSCLC [33]. Previous findings revealed that NEAT1 promoted the epithelial-mesenchymal transition and metastasis in NSCLC via the Wnt/ $\beta$ catenin pathway [25, 34]. However, the association of NEAT1 with the survival of patients with lung cancer has not been reported previously. Consistent with published reports, we found that NEAT1 expression was significantly higher in NSCLC tissues than in adjacent normal tissues (fold-change $=1.7$ ). Moreover, we found the first evidence that NEAT1 can serve as an independent prognostic indicator for patients with NSCLC (unpublished data). To our knowledge, the remaining 3 lncRNAs (lnc-GAN1, ASLNC11245, and 


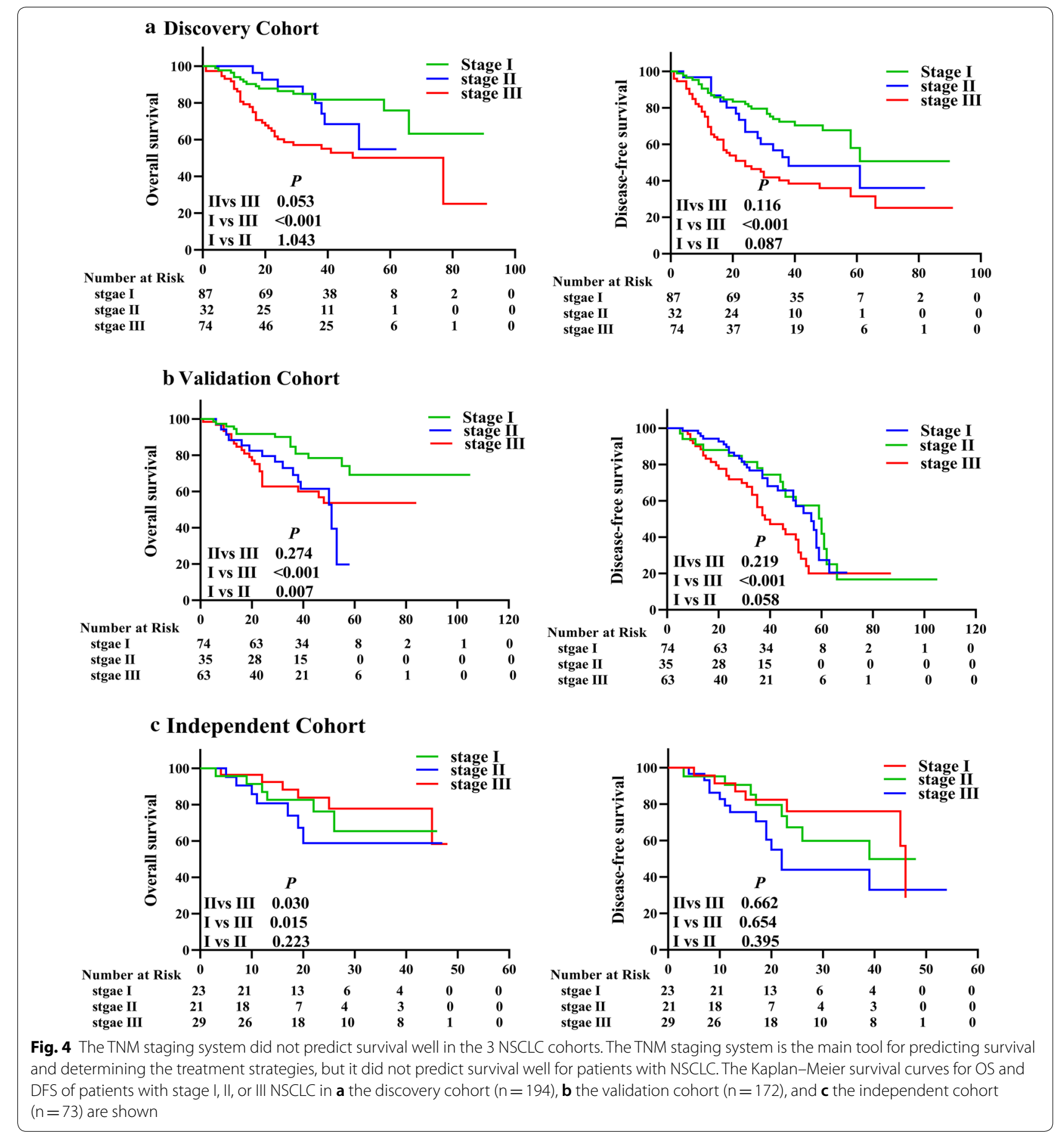

GSO_1539832_023) in the prognostic 4-IncRNA signature have not been functionally annotated. In our study, these 3 lncRNAs were significantly down-regulated in lung cancer tissues compared with adjacent normal tissues (fold-change $=0.39,0.75$, and 0.47 , respectively), and high expression levels of these lncRNAs could serve as indicators for a good prognosis of patients with NSCLC.

Current treatment strategies for lung cancer have led to a comprehensive approach that includes surgery, radiotherapy, chemotherapy, targeted therapy, gene therapy, and immunotherapy [35, 36]. Based on insights gained into the molecular mechanisms underlying NSCLC in 


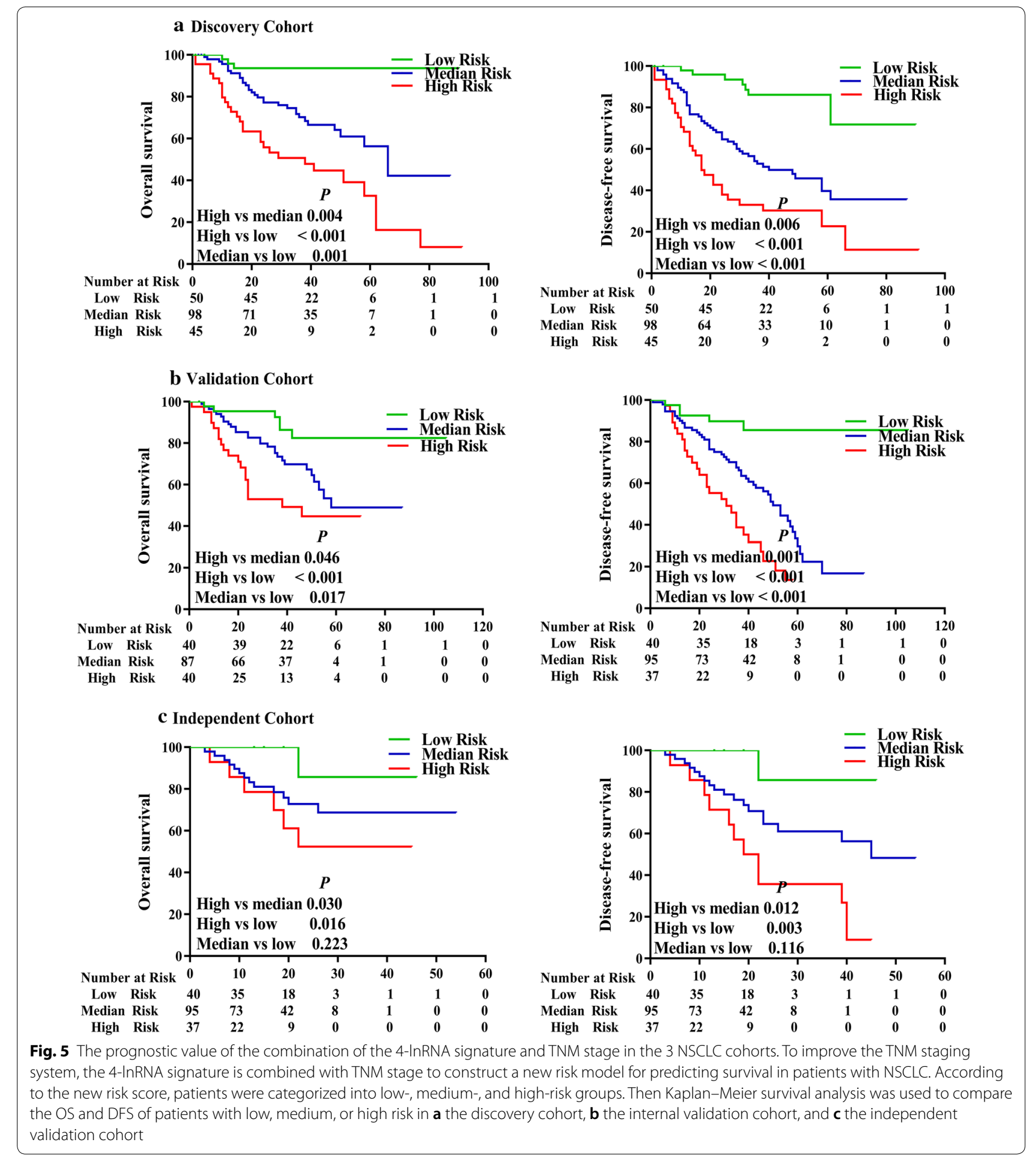

the past 10 years, common mutations in genes encoding EGFR-TKIs (EGFR tyrosine kinase inhibitors), programmed cell death protein 1 , and members of the epidermal growth factor receptor super-family have been treated clinically with targeted tyrosine-kinase inhibitors [37-43]. Even though these targeted therapies have improved the survival rates and quality of life of patients with NSCLC, their effects are far from satisfactory. Most patients exhibit drug resistance or disease progression after receiving treatment for a certain period of time [44, 45]. Therefore, specific biomarkers for monitoring therapeutic responses in patients with NSCLC are urgently 


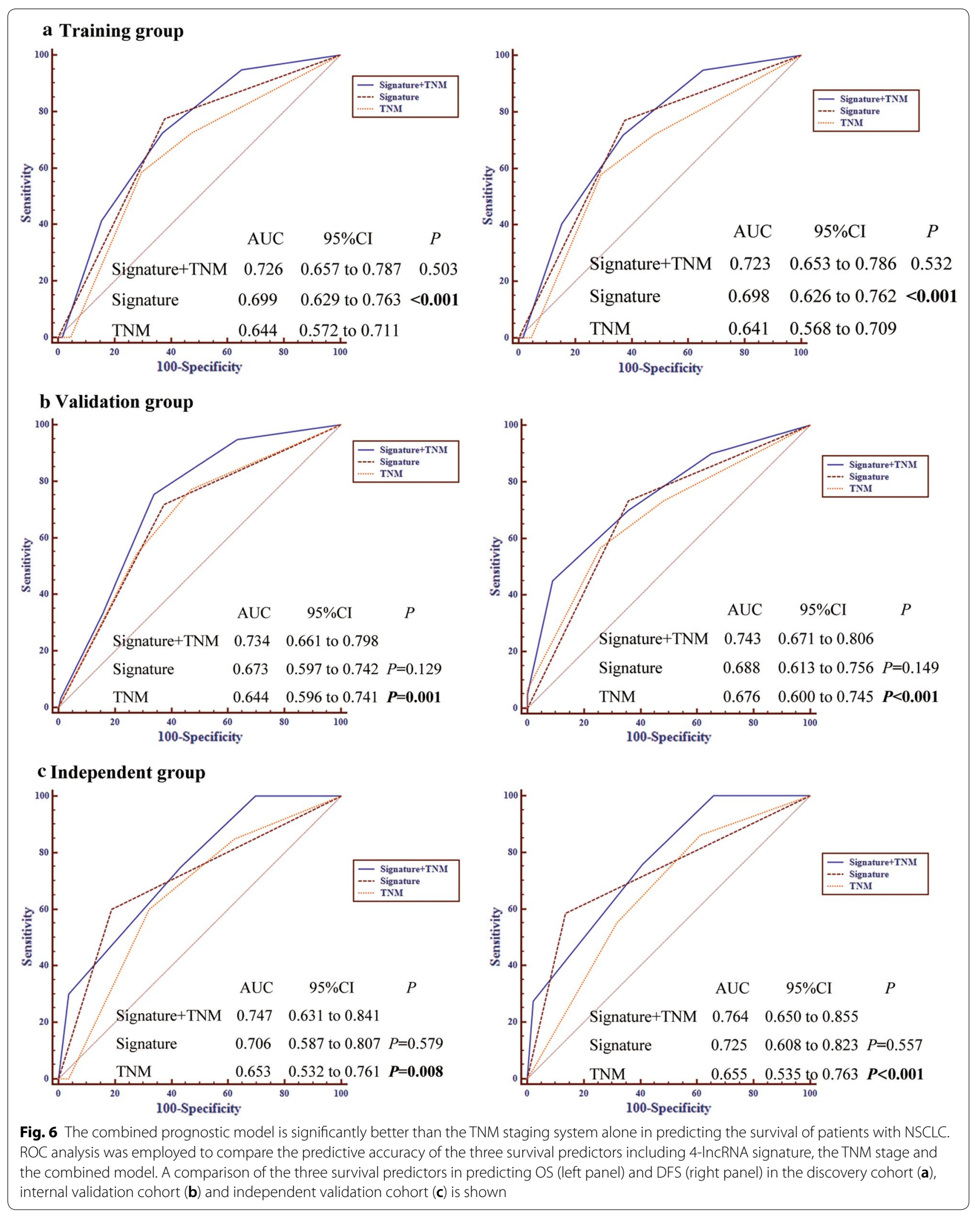


needed. By applying microarray and RNA-seq technology in cancer research, numerous molecular biomarkers have been identified that can predict the responses to specific treatment regimens [46-48]. Of the 4-lncRNA signature identified in this study, NEAT1 was significantly up-regulated in paclitaxel-resistant NSCLC cells and contributed to paclitaxel resistance by activating the Akt/mTORsignaling pathway [49]. Recent data showed that NEAT1 can inhibit apoptosis in multiple myeloma cells by regulating genes involved in DNA-repair processes, including the homologous-recombination pathway, suggesting its association with drug resistance [49]. Therefore, NEAT1, a component of our 4-IncRNA signature, may play an important role in NSCLC.

Although the 4-lncRNA prognostic signature is a novel and potentially powerful predictor for survival in NSCLC patients, further prospective validation studies in larger cohorts and clinical trials are still required. This study also has other limitations. First, although the 4-lncRNA signature was identified in a large number of NSCLC samples from 2 different regions of China, the signature still needs to be validated in a larger prospective multicenter study, involving patients from more institutions and other countries. Second, the efficacy of models based on multiple types of markers are thought to provide better prognostic value than a single type of marker. Thus, further study will be conducted to identify a multi-gene panel by integrating lncRNAs, microRNAs, and messenger RNAs, with the aim of obtaining a more accurate prognostic assessment of NSCLC. Finally, further experiments need to be performed to elucidate the characteristics and functions of the identified prognostic lncRNAs.

\section{Conclusions}

In this study, our findings reveal a tumor-specific IncRNA expression profile in NSCLC tissues and a novel prognostic signature based on 4 lncRNAs, which is a powerful and independent predictor of OS and DFS in patients with NSCLC. Moreover, a new prognostic model is developed by combining the 4-IncRNA signature and TNM stage to refine the current staging system and to improve the predictive performance. The results of our study suggest that the 4-lncRNA classifier might serve as a precise predictive biomarker for selecting high-risk patients who might benefit from adjuvant therapy and thus guide the personalized management of patients with NSCLC.

\section{Supplementary information}

Supplementary information accompanies this paper at https://doi. org/10.1186/s12967-020-02485-8.

Additional file 1. Additional 2 tables and 1 figures.

\section{Abbreviations}

ADC: Adenocarcinoma; DFS: Disease-free survival; FDR: False-discovery rate; GEO: Gene Expression Omnibus; IQR: Inter-quartile range; IncRNA: Long noncoding RNA; NSCLC: Non-small cell lung carcinoma; OS: Overall survival; qRTPCR: Quantitative reverse transcriptase-polymerase chain reaction; RNA-seq: RNA-sequencing; ROC: Receiver operating characteristic; SAM: Significance Analysis of Microarrays; SCC: Squamous cell carcinoma; SD: Standard deviation; SDS: Sodium dodecyl sulfate; SSC: Saline-sodium citrate; TCGA: The Cancer Genome Atlas; TNM: Tumor, nodes, and metastases.

\section{Acknowledgements \\ We are grateful to Mr. Qing-Feng Zhang for his help in bioinformatics analysis., a postgraduates of Sun Yat-Sen University. \\ Authors' contributions \\ HYW, SJM, and XRL conceived and designed this study; RQW and XRL performed experiments, analyzed and interpreted data, and wrote the manu- script; $\mathrm{MYZ}$ and $\mathrm{LH}$ designed the microarray and analyzed the microarray data; CLG, NNZ, YH, RLL, ZL, DC, LJZ and ZSW collected clinical samples, interpreted data and clinical information; SJM improved and revised the manuscript; HYW analyzed and interpreted data, supervised experiments, and wrote the manu- script. All authors read and approved the final manuscript.}

\section{Funding}

This study was supported by National Natural Science Foundation of China (Grant numbers 81772991, 81572466, and 81372564 to HYW; 81772884 to MSJ).

Availability of data and materials

All data in our study are available upon request.

Ethics approval and consent to participate

The study was approved by the Research Ethics Committee of Sun Yat-Sen University Cancer Center. The research was conducted according to all ethical standards, and written informed consent was obtained from all patients.

\section{Consent for publication}

Consent to publish was obtained from all authors.

\section{Competing interests}

The authors declare that they have no competing interests.

\section{Author details}

${ }^{1}$ State Key Laboratory of Oncology in South China, Collaborative Innovation Center for Cancer Medicine, Sun Yat-Sen University Cancer Center, Guangzhou 510060, China. ${ }^{2}$ Department of Gynecology and Obstetrics, Renji Hospital, Medical School of Shanghai Jiaotong University, Shanghai, China. ${ }^{3}$ Department of Cancer Biotherapy Center, The Third Affiliated Hospital of Kunming Medical University (Tumor Hospital of Yunnan Province), Kunming, Yunnan, China. ${ }^{4}$ Department of Oncology, The Second Affiliated Hospital of Nanchang University, Nanchang, China. ${ }^{5}$ Department of Medical Oncology, Sun Yat-Sen University Cancer Center, Guangzhou 510060, China. ${ }^{6}$ Department of Thoracic Oncology, Sun Yat-Sen University Cancer Center, Guangzhou 510060, China. ${ }^{7}$ State Key Laboratory of Oncology in South China, Sun Yat-Sen University Cancer Center, 651 Dongfeng East Road, Building 2, Rm 704, Guangzhou 510060, China.

Received: 22 April 2020 Accepted: 13 August 2020

Published online: 20 August 2020

References

1. Siegel RL, Miller KD, Jemal A. Cancer statistics, 2020. CA Cancer J Clin. 2020;70:7-30.

2. Rusch VW, Chansky K, Kindler HL, Nowak AK, Pass HI, Rice DC, Shemanski L, Galateau-Salle F, McCaughan BC, Nakano T, et al. The IASLC Mesothelioma Staging Project: proposals for the M descriptors and for revision of the TNM stage groupings in the forthcoming (Eighth) edition of the TNM classification for mesothelioma. J Thorac Oncol. 2016;11:2112-9. 
3. Herbst RS, Morgensztern D, Boshoff C. The biology and management of non-small cell lung cancer. Nature. 2018;553:446-54.

4. Allemani C, Matsuda T, Di Carlo V, Harewood R, Matz M, Niksic M, Bonaventure A, Valkov M, Johnson CJ, Esteve J, et al. Global surveillance of trends in cancer survival 2000-14 (CONCORD-3): analysis of individual records for 37513025 patients diagnosed with one of 18 cancers from 322 population-based registries in 71 countries. Lancet. 2018;391:1023-75.

5. Carter BW, Lichtenberger JP 3rd, Benveniste MK, de Groot PM, Wu CC, Erasmus JJ, Truong MT. Revisions to the TNM staging of lung cancer: rationale, significance, and clinical application. Radiographics. 2018;38:374-91

6. Reck M, Rabe KF. Precision diagnosis and treatment for advanced nonsmall-cell lung cancer. N Engl J Med. 2017;377:849-61.

7. Wei MM, Zhou GB. Long non-coding RNAs and their roles in non-smallcell lung cancer. Genom Proteom Bioinform. 2016;14:280-8.

8. Fang B, Mehran RJ, Heymach JV, Swisher SG. Predictive biomarkers in precision medicine and drug development against lung cancer. Chin J Cancer. 2015;34:295-309.

9. Shukla S, Evans JR, Malik R, Feng FY, Dhanasekaran SM, Cao X, Chen G, Beer DG, Jiang H, Chinnaiyan AM. Development of a RNA-Seq based prognostic signature in lung adenocarcinoma. J Natl Cancer Inst. 2017;109:djw200

10. Lin T, Fu Y, Zhang X, Gu J, Ma X, Miao R, Xiang X, Niu W, Qu K, Liu C, Wu Q. A seven-long noncoding RNA signature predicts overall survival for patients with early stage non-small cell lung cancer. Aging. 2018;10:2356-66.

11. Hiley CT, Le Quesne J, Santis G, Sharpe R, de Castro DG, Middleton G, Swanton C. Challenges in molecular testing in non-small-cell lung cancer patients with advanced disease. Lancet. 2016;388:1002-11.

12. Lochowska BA, Nowak D, Bialasiewicz P. Cell-free tumour DNA as a diagnostic and prognostic biomarker in non-small cell lung carcinoma. Adv Respir Med. 2019;87:118-22.

13. Chen HY, Yu SL, Chen CH, Chang GC, Chen CY, Yuan A, Cheng CL, Wang $\mathrm{CH}$, Terng HJ, Kao SF, et al. A five-gene signature and clinical outcome in non-small-cell lung cancer. N Engl J Med. 2007;356:11-20.

14. Yu H, Xu Q, Liu F, Ye X, Wang J, Meng X. Identification and validation of long noncoding RNA biomarkers in human non-small-cell lung carcinomas. JThorac Oncol. 2015;10:645-54.

15. Spizzo R, Almeida Ml, Colombatti A, Calin GA. Long non-coding RNAs and cancer: a new frontier of translational research? Oncogene. 2012:31:4577-87.

16. Khurana E, Fu Y, Chakravarty D, Demichelis F, Rubin MA, Gerstein M. Role of non-coding sequence variants in cancer. Nat Rev Genet. 2016;17:93-108.

17. Mercer TR, Dinger ME, Mattick JS. Long non-coding RNAs: insights into functions. Nat Rev Genet. 2009;10:155-9.

18. Kitagawa M, Kitagawa K, Kotake $Y$, Niida H, Ohhata T. Cell cycle regulation by long non-coding RNAs. Cell Mol Life Sci. 2013;70:4785-94.

19. Lee JT. Epigenetic regulation by long noncoding RNAs. Science. 2012:338:1435-9.

20. Schmitt AM, Chang HY. Long noncoding RNAs in cancer pathways. Cancer Cell. 2016:29:452-63.

21. Gutschner T, Hammerle M, Eissmann M, Hsu J, Kim Y, Hung G, Revenko A, Arun G, Stentrup M, Gross M, et al. The noncoding RNA MALAT1 is a critical regulator of the metastasis phenotype of lung cancer cells. Cancer Res. 2013;73:1180-9.

22. Schmidt LH, Spieker T, Koschmieder S, Schaffers S, Humberg J, Jungen D, Bulk E, Hascher A, Wittmer D, Marra A, et al. The long noncoding MALAT-1 RNA indicates a poor prognosis in non-small cell lung cancer and induces migration and tumor growth. J Thorac Oncol. 2011;6:1984-92.

23. Schmidt LH, Gorlich D, Spieker T, Rohde C, Schuler M, Mohr M, Humberg J, Sauer T, Thoenissen NH, Huge A, et al. Prognostic impact of Bcl-2 depends on tumor histology and expression of MALAT-1 InCRNA in nonsmall-cell lung cancer. J Thorac Oncol. 2014;9:1294-304.

24. Li S, Yang J, Xia Y, Fan Q, Yang KP. Long noncoding RNA NEAT1 promotes proliferation and invasion via targeting miR-181a-5p in non-small cell lung cancer. Oncol Res. 2018;26:289-96.

25. Qi L, Liu F, Zhang F, Zhang S, Lv L, Bi Y, Yu Y. IncRNA NEAT1 competes against let-7a to contribute to non-small cell lung cancer proliferation and metastasis. Biomed Pharmacother. 2018:103:1507-15.
26. Wang HY, Luo M, Tereshchenko IV, Frikker DM, Cui X, Li JY, Hu G, Chu Y, Azaro MA, Lin Y, et al. A genotyping system capable of simultaneously analyzing $>1000$ single nucleotide polymorphisms in a haploid genome. Genome Res. 2005;15:276-83.

27. Wang H, Ach RA, Curry B. Direct and sensitive miRNA profiling from lowinput total RNA. RNA. 2007;13:151-9.

28. Yu SL, Chen HY, Chang GC, Chen CY, Chen HW, Singh S, Cheng CL, Yu CJ, Lee $Y C$, Chen HS, et al. MicroRNA signature predicts survival and relapse in lung cancer. Cancer Cell. 2008;13:48-57.

29. Liu N, Chen NY, Cui RX, Li WF, Li Y, Wei RR, Zhang MY, Sun Y, Huang $\mathrm{BJ}$, Chen $\mathrm{M}$, et al. Prognostic value of a microRNA signature in nasopharyngeal carcinoma: a microRNA expression analysis. Lancet Oncol. 2012:13:633-41.

30. Hu Z, Chen X, Zhao Y, Tian T, Jin G, Shu Y, Chen Y, Xu L, Zen K, Zhang C, Shen $H$. Serum microRNA signatures identified in a genome-wide serum microRNA expression profiling predict survival of non-small-cell lung cancer. J Clin Oncol. 2010;28:1721-6.

31. Zhou M, Guo M, He D, Wang X, Cui Y, Yang H, Hao D, Sun J. A potential signature of eight long non-coding RNAs predicts survival in patients with non-small cell lung cancer. J Transl Med. 2015;13:231.

32. He R, Zuo S. A robust 8-gene prognostic signature for early-stage nonsmall cell lung cancer. Front Oncol. 2019;9:693.

33. Pan LJ, Zhong TF, Tang RX, Li P, Dang YW, Huang SN, Chen G. Upregulation and clinicopathological significance of long non-coding NEAT1 RNA in NSCLC tissues. Asian Pac J Cancer Prev. 2015;16:2851-5.

34. Kong X, Zhao Y, Li X, Tao Z, Hou M, Ma H. Overexpression of HIF-2alphadependent NEAT1 promotes the progression of non-small cell lung cancer through miR-101-3p/SOX9/Wnt/beta-catenin signal pathway. Cell Physiol Biochem. 2019;52:368-81.

35. Kris MG, Gaspar LE, Chaft JE, Kennedy EB, Azzoli CG, Ellis PM, Lin SH, Pass $\mathrm{HI}$, Seth R, Shepherd FA, et al. Adjuvant systemic therapy and adjuvant radiation therapy for stage I to IIIA completely resected non-small-cell lung cancers: American Society of Clinical Oncology/Cancer Care Ontario Clinical Practice Guideline Update. J Clin Oncol. 2017;35:2960-74.

36. Camidge DR, Doebele RC, Kerr KM. Comparing and contrasting predictive biomarkers for immunotherapy and targeted therapy of NSCLC. Nat Rev Clin Oncol. 2019;16:341-55.

37. Best MG, Sol N, Kooi I, Tannous J, Westerman BA, Rustenburg F, Schellen P, Verschueren H, Post E, Koster J, et al. RNA-seq of tumor-educated platelets enables blood-based pan-cancer, multiclass, and molecular pathway cancer diagnostics. Cancer Cell. 2015;28:666-76.

38. Gasparini P, Cascione L, Landi L Carasi S, Lovat F, Tibaldi C, Ali G, D'Incecco A, Minuti G, Chella A, et al. microRNA classifiers are powerful diagnostic/ prognostic tools in ALK-, EGFR-, and KRAS-driven lung cancers. Proc Natl Acad Sci USA. 2015;112:14924-9.

39. Socinski MA, Jotte RM, Cappuzzo F, Orlandi F, Stroyakovskiy D, Nogami N, Rodriguez-Abreu D, Moro-Sibilot D, Thomas CA, Barlesi F, et al. Atezolizumab for first-line treatment of metastatic nonsquamous NSCLC. N Engl J Med. 2018;378:2288-301.

40. Soria JC, Ohe Y, Vansteenkiste J, Reungwetwattana T, Chewaskulyong B, Lee KH, Dechaphunkul A, Imamura F, Nogami N, Kurata T, et al. Osimertinib in untreated EGFR-mutated advanced non-small-cell lung cancer. N Engl J Med. 2018;378:113-25.

41. Wu YL, Cheng Y, Zhou X, Lee KH, Nakagawa K, Niho S, Tsuji F, Linke R, Rosell R, Corral J, et al. Dacomitinib versus gefitinib as first-line treatment for patients with EGFR-mutation-positive non-small-cell lung cancer (ARCHER 1050): a randomised, open-label, phase 3 trial. Lancet Oncol. 2017:18:1454-66.

42. Kim HS, Mendiratta S, Kim J, Pecot CV, Larsen JE, Zubovych I, Seo BY, Kim J, Eskiocak B, Chung H, et al. Systematic identification of molecular subtype-selective vulnerabilities in non-small-cell lung cancer. Cell. 2013:155:552-66.

43. Arbour KC, Riely GJ. Systemic therapy for locally advanced and metastatic non-small cell lung cancer: a review. JAMA. 2019;322:764-74.

44. Hensing TA, Schell MJ, Lee JH, Socinski MA. Factors associated with the likelihood of receiving second line therapy for advanced non-small cell lung cancer. Lung Cancer. 2005;47:253-9.

45. Zhang L, Li S, Choi YL, Lee J, Gong Z, Liu X, Pei Y, Jiang A, Ye M, Mao M, et al. Systematic identification of cancer-related long noncoding RNAs and aberrant alternative splicing of quintuple-negative lung adenocarcinoma through RNA-seq. Lung Cancer. 2017;109:21-7. 
46. Singal G, Miller PG, Agarwala V, Li G, Kaushik G, Backenroth D, Gossai A, Frampton GM, Torres AZ, Lehnert EM, et al. Association of patient characteristics and tumor genomics with clinical outcomes among patients with non-small cell lung cancer using a clinicogenomic database. JAMA 2019;321:1391-9.

47. Hirsch FR, Scagliotti GV, Mulshine JL, Kwon R, Curran WJ Jr, Wu YL, PazAres L. Lung cancer: current therapies and new targeted treatments. Lancet. 2017;389:299-311.

48. Sandoval J, Mendez-Gonzalez J, Nadal E, Chen G, Carmona FJ, Sayols S, Moran S, Heyn H, Vizoso M, Gomez A, et al. A prognostic DNA methylation signature for stage I non-small-cell lung cancer. J Clin Oncol. 2013:31:4140-7.
49. Li B, Gu W, Zhu X. NEAT1 mediates paclitaxel-resistance of non-small cell of lung cancer through activation of Akt/mTOR signalling pathway. J Drug Target. 2019;27:1061-7.

\section{Publisher's Note}

Springer Nature remains neutral with regard to jurisdictional claims in published maps and institutional affiliations.
Ready to submit your research? Choose BMC and benefit from:

- fast, convenient online submission

- thorough peer review by experienced researchers in your field

- rapid publication on acceptance

- support for research data, including large and complex data types

- gold Open Access which fosters wider collaboration and increased citations

- maximum visibility for your research: over $100 \mathrm{M}$ website views per year

At BMC, research is always in progress.

Learn more biomedcentral.com/submissions 